\title{
Techno-Economic and Sustainability Analysis of Potential Cooling Methods in Irish Data Centres
}

\author{
Lee Gibbons ${ }^{1}$, Tim Persoons ${ }^{2}$, Sajad Alimohammadi1,2* \\ ${ }^{1}$ School of Mechanical and Design Engineering, Technological University Dublin, Dublin, Ireland \\ ${ }^{2}$ Department of Mechanical, Manufacturing \& Biomedical Engineering, Trinity College Dublin, Dublin, Ireland \\ Email: *sajad.alimohammadi@tudublin.ie
}

How to cite this paper: Gibbons, L., Persoons, T. and Alimohammadi, S. (2021) Techno-Economic and Sustainability Analysis of Potential Cooling Methods in Irish Data Centres. Journal of Electronics Cooling and Thermal Control, 10, 35-54.

https://doi.org/10.4236/jectc.2021.103003

Received: June 3, 2021

Accepted: August 1, 2021

Published: August 4, 2021

Copyright (c) 2021 by author(s) and Scientific Research Publishing Inc. This work is licensed under the Creative Commons Attribution International License (CC BY 4.0).

http://creativecommons.org/licenses/by/4.0/

\begin{abstract}
$11 \%$ of Irish electricity was consumed by data centres in 2020 . The Irish data centre industry and the cooling methods utilised require reformative actions in the coming years to meet EU Energy policies. The resell of heat, alternative cooling methods or carbon reduction methods are all possibilities to conform to these policies. This study aims to determine the viability of the resell of waste heat from data centres both technically and economically. This was determined using a novel application of thermodynamics to determine waste heat recovery potential in Irish data centres, and the current methods of heat generation for economical comparison. This paper also explores policy surrounding waste heat recovery within the industry. The Recoverable Carnot Equivalent Power (RCEP) is theoretically calculated for the three potential cooling methods for Irish data centres. These are air, hybrid, and immersion cooling techniques. This is the maximum useable heat that can be recovered from a data centre rack. This study is established under current operating conditions which are optimised for cooling performance, that air cooling has the highest potential RCEP of $0.39 \mathrm{~kW} /$ rack. This is approximately $8 \%$ of the input electrical power that can be captured as useable heat. Indicating that Irish data centres have the energy potential to be heat providers in the Irish economy. This study highlighted the technical and economic aspects of prevalent cooling techniques and determined air cooling heat recovery cost can be reduced to $0.01 € / \mathrm{kWh}_{\text {th }}$ using offsetting. This is financially competitive with current heating solutions in Ireland.
\end{abstract}

\section{Keywords}

Ireland, Data Centres, Techno-Economic, Novel Cooling Methods, Heat Resell, Sustainability, Energy Demand 


\section{Introduction}

Irish data centres consume an estimated $11 \%$ of Irish generated electricity. These servers can be utilised as data storage or compute power. This is the source of the requirement for cooling. Data centre cooling is responsible for $11 \%$ [1] to $40 \%$ [2] of the total input electricity.

There is a significant investment for data centres in Ireland, with a projected $127 \%$ increase in data centres, when considering data centres under construction and with planning permission obtained in 2020 [3]. There is a requirement for metrics such as Power Utilization Effectiveness (PUE) to be consolidated to enhance energy effectiveness in Irish data centres. Various organizations, along with the government, are aiming to reform sustainability goals, tackle the rapid growth and minimise the negative environmental impacts data centres could pose during this rapid growth.

This article is the second part of a broad-ranging study on the Irish data centre industry's effects on the Irish economy, policy and energy sector. The first part considered heat rates and potential cooling methods for Irish data centres [4]. This paper is a follow-on of a conference paper [4] which presented by authors in the $25^{\text {th }}$ International Workshop on Thermal Investigations of ICs and Systems (Therminic) in 2019. The background and calculations have been updated for 2020, in addition to finalised method of exergy analysis. This article considers the three core cooling methods and their efficacy on energy management for the objectives listed below:

- Explore the Irish data centre market landscape, and future industry projections.

- Investigate a comparison between the three core cooling methods using entropy generation, and exergy analysis. To determine the engineering feasibility of data centre waste heat recovery in Ireland.

- Perform a comparative analysis of recovered heat cost, and its applications for the cooling methods; to determine the financial feasibility of data centre waste heat recovery and its applications in Ireland.

\subsection{Irish Data Centre Facility Energy Usage}

Several multinational Information Technology (IT) companies have significant investments in Ireland. Cool climate has been cited as one of the specific reasons for investment in Ireland's data centre industry. The mean temperature for 2019 in the county Dublin (where most data centres are located) was $10.4^{\circ} \mathrm{C}$ [5], the highest average was July at $15.9^{\circ} \mathrm{C}$ [5] thus free economiser air cooling can be used with great effect.

In Ireland, there are 60 operational data centres, with an additional 38 in construction or planning [6] as of July 2020.

Equation (1) from Initial studies [4] can be used to calculate the percentage of all Irish data centre electricity usage as a function of the entire Republic of Ireland power grid. This is $3.1 \mathrm{TWh}$ per annum. This calculation uses a Utilisation 
factor per year (operational percentage, $\mathrm{U}_{\text {factor }}$ ) of 0.5 (facility running for $50 \%$ of the year) [3].

An evaluation of the types of data centre is as follows: $43.3 \%$ hyperscale, $6.7 \%$ colocation wholesale, $25 \%$ colocation, $25 \%$ private, and $0 \%$ edge [7]. It is important to note, that hyperscale data centres are within the lower percentage of cooling electricity consumption range (11\% [1] to 40\% [2]); and hyperscale data centres saw a reduction in overall market share in Q1 2020. This could mean Irish data centres overall electricity profile might grow significantly in the coming years due to smaller less efficient data centres becoming operational.

The maximum grid power demand for Irish data centres is estimated at 708 MW, gathered from the Q2 2020 Host in Ireland report [7]. The grid power demand for Ireland ( $\left.\mathrm{P}_{\text {Ireland }}\right)$ in 2019 was 27.1 TWh per annum [8]. The utilisation factor $\left(\mathrm{U}_{\text {factor }}\right)$ of a generic Irish data centre is estimated to be 0.5 [7]. It is important to note that EirGrid in 2017 used a utilisation factor of 0.75 [9], while Host in Ireland uses an updated figure of 0.5 [7]. The 0.75 figure is more likely in non-hyperscale data centres due to their operating business model favouring high uptimes, hyperscale data centres do not favour high uptimes, rather flexibility. Applying the same method from the initial study [4] gives a figure of $11.5 \%$ of total Irish.

The 3.1 TWh per annum by the average carbon dioxide intensity for Ireland's power sources in 2019 was $0.375 \mathrm{kgCO}_{2} / \mathrm{kWh}$ [8]. The current emissions from the data centre industry are approximately 1.1 million tonnes of $\mathrm{CO}_{2}$ per annum. Note, Ireland has a higher amount of hyperscale data centres than other countries, thus the carbon emission estimated in this article can be lower than calculated [7].

Power utilisation effectiveness (PUE) is the entire data centre demand divided by the IT demand from the electronic computing and processing equipment [10]. The minimum PUE score is 1.0 (in the absence of waste heat recuperation). The PUE formula is utilised in further detail below.

\subsection{The Future of Irish Data Centres}

If no more data centres were added to the ones currently planned that is 98 data centres in Ireland, a total capacity of 1965 MW by 2027 is predicted [11]. Host in Ireland ${ }^{1}$ forecasted that by 2025 the load will be $1700 \mathrm{MW}$ [3], indicating the forecasted number might be higher due to rapid industry growth. Applying the electricity consumption percentage model from Section 1.1 and using EirGrid's forecasts, by 2027, Ireland's electrical median consumption will be $40 \mathrm{TWh}$ per annum [12]. Data centres could account for $30.98 \%$ of nationwide electricity consumption, supporting EirGrid's projections on data centre electrical consumption by 2027. It highlights the need for more efficient cooling methods for the data centres to reduce their overall electricity consumption. Figure 1 shows the yearly expected growth.

\footnotetext{
${ }^{1}$ https://www.hostinireland.com/about
} 


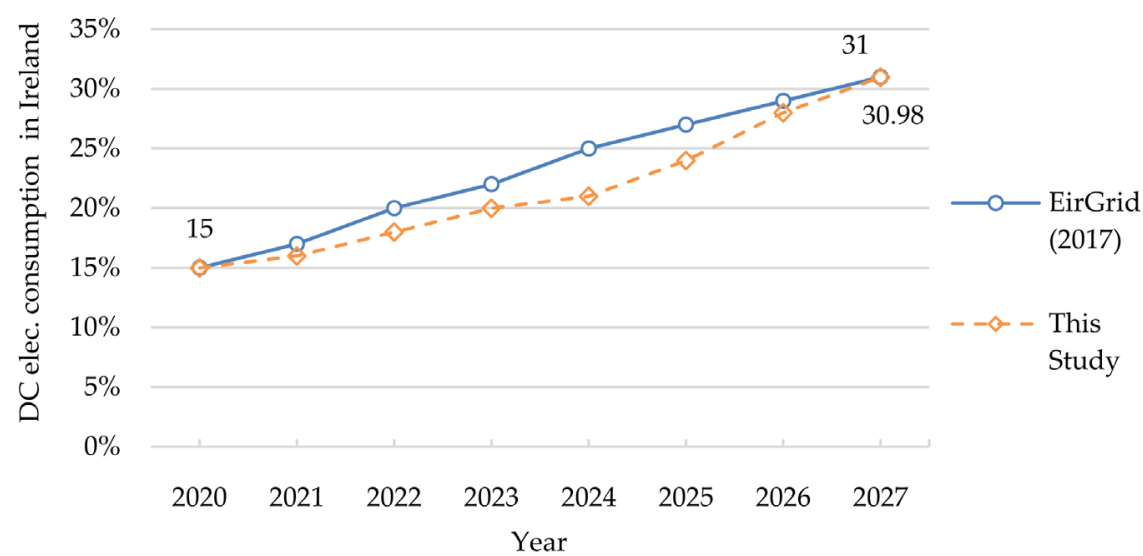

Figure 1. Data centre electricity consumption as a percentage of Irish total electricity consumption projected to 2027 (this study) and compared to EirGrid's projections of the same parameter.

\subsection{Cooling Technologies}

Given the high electricity consumption of Irish data centres, it is a matter of urgency to reduce or reuse the energy from data centres. The cooling load in a data centre on average is $11 \%$ [1] to $40 \%$ [2] of the total power load.

\subsubsection{Air Cooling}

Air cooling utilises fans to pass air over the server blade. This cooling technique is favoured in the Irish data centre market due to the low atmospheric temperatures. The European Union (EU) survey of 289 data centres published in 2017 determined: 170 had zero free air-cooling techniques utilised, 78 utilised a single technique of free air cooling, and 41 utilised a mixture of two supplementary free cooling options [13].

ASHRAE TC9.9 is an industry-based set of guidelines on the best practices of data centres. In 2018, EU code of conduct on data centre energy efficiency was released. The EU recommends the minimum inlet air temperature to be in the range of $10^{\circ} \mathrm{C}$ to $35^{\circ} \mathrm{C}$ [14]. This is based on ASHRAE A2 class which was determined to be the optimal energy savings class in the EU report. The recent growth in the Irish industry means most data centres are likely class A2 compliant and not legacy. Similar standards are NEBS and ETSI which are less popular in the industry.

\subsubsection{Two-Phase Dielectric Liquid Immersion Cooling}

The two prevalent immersion cooling techniques are bath (sometimes called pool) and enclosure. Bath immersion is shown in Figure 2. The favoured immersion cooling method is a bath (called two-phase sometimes) due to its increased performance [15]. It operates under a boil and condenses cycle. The dielectric liquid boils and condenses causing convection currents. The vaporised dielectric removes the heat. Figure 2 shows a horizontal configuration, but vertical orientation is also possible. Enclosure immersion can be passive or pumped, while it is less prevalent due to the higher cost and more materials required. 


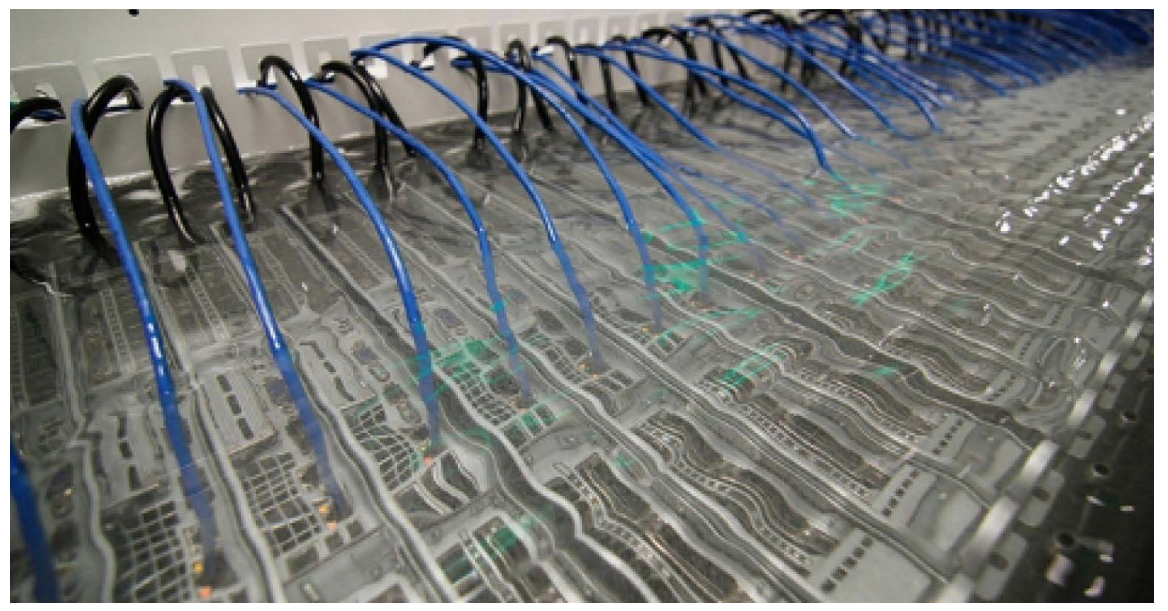

Figure 2. Bath immersion cooling for blade servers [16].

The Open Compute Project (OCP) is an open-source standard for immersion cooling in data centres and is in development currently. This standard is on the operation and optimal conditions for an immersion cooled data centre. The aim is to match the layout of ASHRAE TC9.9 operating classes in the OCP standard. All immersion data centres currently require developing their operating conditions, limiting immersion cooling adoption as it is an additional entry cost.

\subsubsection{Hybrid (Air/Liquid) Cooling}

Hybrid cooling utilises on-surface contact hot spot cooling. The pumped cold liquid is used on the server blade hot spots and the airflow of the fan to cool the rest of the motherboard. The CPU is the primary target device on the server blade as described by Ebrima et al. (2014). The CPU is the highest temperature component; thus, it would benefit from concentrated cooling. There are two broad configurations for hybrid cooling: rack cooling and centralised distribution unit (CDU), as shown in Figure 3. Rack cooling allows isolated cooling, CDU allows facility wide cooling.

There are no standards on hybrid cooling yet due to the low market adoption and relatively high adoption cost (fans for air portion cooling, and pumps for water portion cooling).

\subsection{Data Centre Type and Impact of Standards on Their Operating Conditions in Ireland}

Some colocation data centres could require external certification like Uptime Institutes tier operation classification for marketing to customers, limiting the operating condition freedom that hyperscale data centres can use. Hyperscale data centres do not require marketing to gain customers due to operating and using their own data centres. This means hyperscale data centres cooling parameters can be changed independently from ASHRAE TC9.9 or NEBS standards. Hyperscale data centres benefit from more efficient cooling and thus lower PUE scores from this independence. For example, Google's (hyperscale data centre) has some of the lowest PUE scores in the world at an average of 1.11 [1]. 


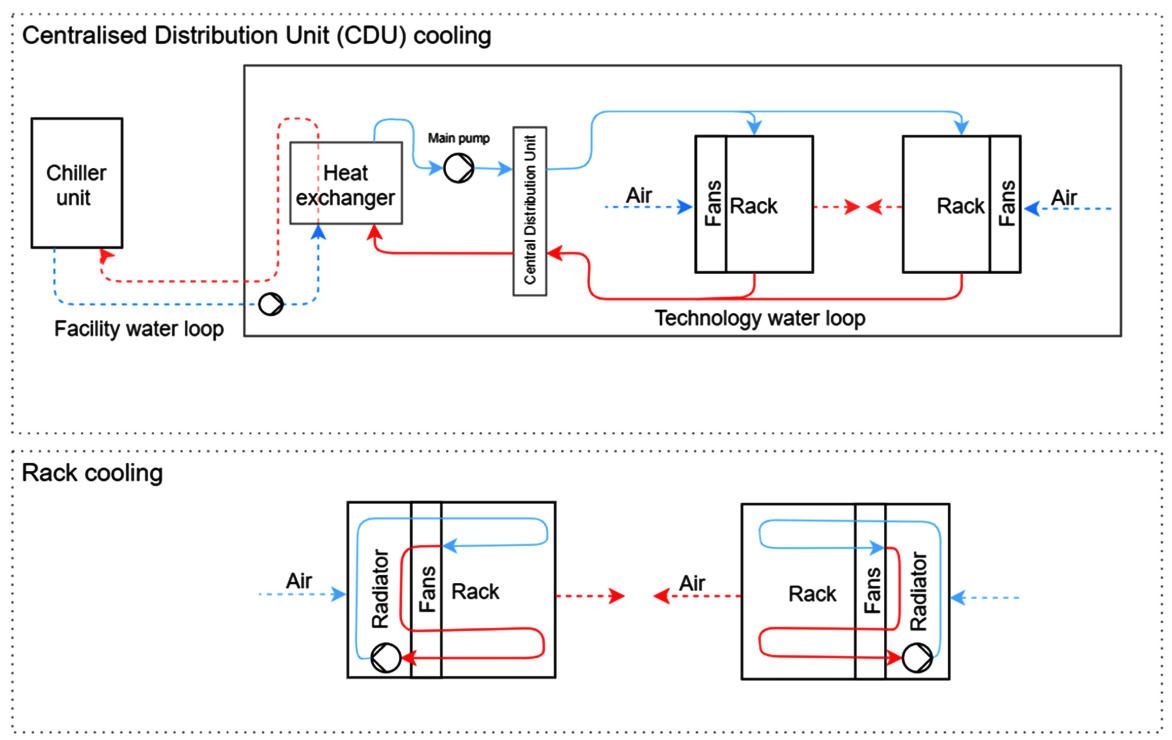

Figure 3. Hybrid CDU cooling, and rack cooling line diagram comparison.

\section{Materials and Methods}

\subsection{Thermodynamic Analysis}

The disorder created during a state-change (inlet to outlet) process is called entropy generation. Entropy generation is the quantity of useful energy dissipated from a process [17]. A portion of energy dissipated from a process can be then recovered, this is called exergy.

It is important to note that although entropy generation is operational condition dependent, it is not an indication of waste heat recovery potential. Exergy indicates the waste heat recovery potential. Entropy generation is the sum of losses, exergy is the portion of that loss that can be recovered again, this relationship is shown in Equation (7).

The thermodynamic assumptions help to generalise the model for a broad application in the data centre market. The air and hybrid systems assumptions are: 1) Steady-state flow, steady-state thermal properties; 2) The electronics components (heat sources) are adiabatic to surrounding areas (mounts and rack cages). All heat transfer is to the coolant; 3) The two systems have the mass transfer between the facility surroundings and rack. Thus, both systems are open loop.

For the two-phase immersion, assumptions 1-3 are relevant, in addition to (4) The data centre has no lighting load or power delivery losses. This would achieve the lowest possible PUE score. Therefore, all excess power is for cooling.

\subsubsection{Air Cooling}

Figure 4 shows the boundary conditions and analysis points. Table 1 shows the typical operating conditions for air cooling.

The core theory of this cooling analysis is an entropy balance applied as described by Cengel et al. [17]. With fans supplying a constant flow, the total entropy change $\left(\Delta S_{\text {sys }}\right)$ is zero as the conditions are steady. There is mass and heat 


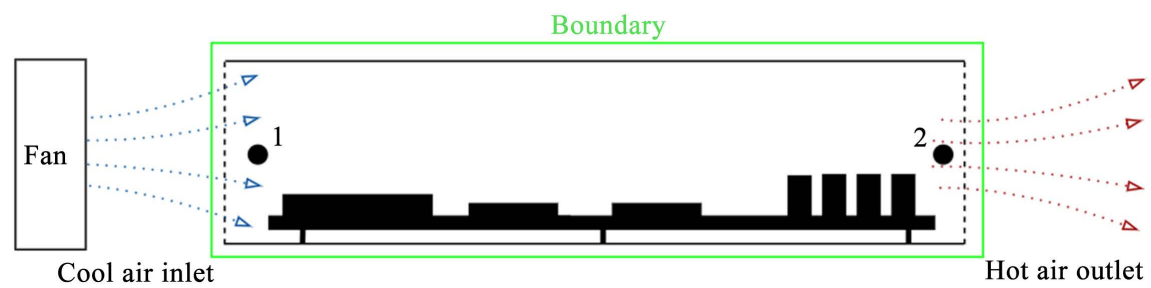

Figure 4. Air cooled blade server boundary conditions.

Table 1. Air cooling operating conditions for a typical data centre rack, mass flow rate ( $m_{a}$ is an average from four EU sources to account for deviations in operation).

\begin{tabular}{ccccc}
\hline Parameter & Notation & Value & Units & Source \\
\hline Inlet temperature & $T_{\text {in a }}$ & 290.15 & $\mathrm{~K}$ & {$[18]$} \\
Outlet temperature & $T_{\text {outa }}$ & 303.15 & $\mathrm{~K}$ & {$[18]$} \\
Ambient temperature & $T_{\text {amb }}$ & 294.15 & $\mathrm{~K}$ & {$[14]$} \\
Specific heat capacity of air & $C_{p a}$ & 1.00475 & $\mathrm{~kJ} / \mathrm{kg} \cdot \mathrm{K}$ & {$[19]$} \\
Mass flow rate of air & $m_{a}$ & 0.595 & $\mathrm{~kg} / \mathrm{s}$ & {$[20][21][22][23]$} \\
\hline
\end{tabular}

transfer within the system. Thus, entropy in and out expands to account for this, as shown in Equation (1).

$$
S_{g e n}=\left[\frac{Q}{T_{a m b}}+\dot{m}_{o} S_{o}-\dot{m}_{i} S_{i}\right]
$$

The mass flow rate is constant from the inlet to outlet, thus Equation (1) can be further reduced to Equation (2), where $\dot{m}$ is the mass flow rate over the server. $\Delta S$ is the entropy change from the inlet to the outlet.

$$
S_{g e n}=\frac{Q}{T_{a m b}}+\dot{m}(\Delta S)
$$

The gas (air) is assumed ideal, where $C_{p}$ is the specific heat capacity of air. $T_{2}$ and $T_{1}$ are the temperature at inlet and exhaust, respectively. $r$ is the universal gas constant of air, it is $0.287 \mathrm{~kJ} / \mathrm{kg} \cdot \mathrm{K}$ [19]. $P_{2}$ and $P_{1}$ are the pressures at inlet and exhaust, respectively. This is shown in Equation (3).

$$
\Delta S=C_{p} \ln \left(\frac{T_{2}}{T_{1}}\right)-r \ln \left(\frac{P_{2}}{P_{1}}\right)
$$

There is no pressure change due to the flow being open to the atmosphere on both sides (no constraining volume) thus Equation (3) reduces to Equation (4). It is assumed all entropy generation is from heat transfer.

$$
\Delta S=C_{p} \ln \left(\frac{T_{2}}{T_{1}}\right)-0
$$

The entropy generation is determined using the final form in Equation (5), with the inputs derived from Table 1 above. The final entropy generation from using Equation (5) and the data gives $0.0526 \mathrm{~kJ} / \mathrm{kg} \cdot \mathrm{K}$. 


$$
S_{\text {gen }}=\frac{\left[\dot{m} C_{p}\left(T_{2}-T_{1}\right)\right]}{T_{a m b}}+\dot{m}\left(C_{p} \ln \left(\frac{T_{2}}{T_{1}}\right)\right)
$$

In this study, there is no waste heat recovery unit, this means no exergy is recovered and all exergy is lost within the boundary conditions. The exergy balance equation from Cengel et al. is shown in Equation (6) [17].

$$
\Delta X_{\text {system }}=\Delta X_{\text {mass, work, heat }}-X_{\text {Destroyed }}
$$

Exergy from mass, work and heat transfer is zero within this study; due to nothing being transferring across the boundary. If a waste heat recovery unit were used, then net exergy could be calculated. The remaining constants are shown in Equation (7). The final exergy destroyed using Equation (7) and the data from Table 1 gives $15.47 \mathrm{~kJ} / \mathrm{kg}$ for air cooling.

$$
X_{\text {system }}=X_{\text {Destroyed }}=T_{a m b} S_{\text {gen }}
$$

New cooling methods such as Linear Air Amplifier Technology (LAAT) [24] reduce fan counts in the data center as such could provide similar cooling potential to traditional rotary fans using less electricity; this method would favor heat capture energy economy.

\subsubsection{Hybrid Cooling}

Figure 5 shows the boundary conditions and analysis points for hybrid cooling. The air loop is 1 and 2 and the water loop is 3 and 4 . Table 2 shows the typical operating conditions for hybrid cooling. Important to note in Table 2 is the

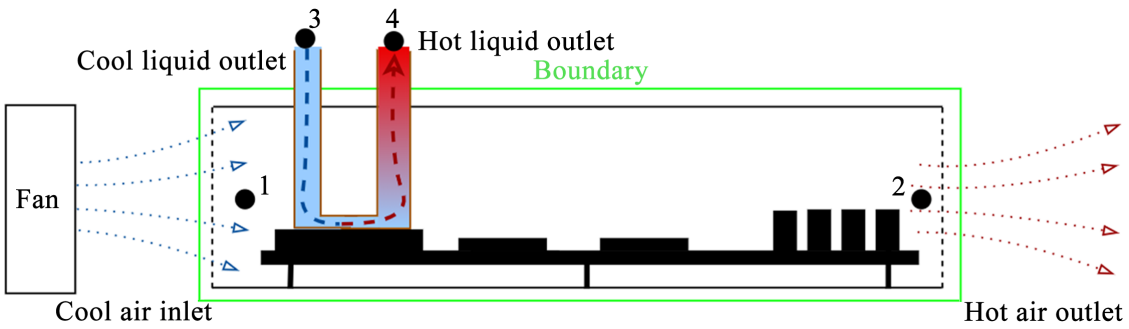

Figure 5. Hybrid cooling 1U blade server.

Table 2. Hybrid cooling data centre rack study parameters, the calculations are based on a $42 \mathrm{U}$ rack.

\begin{tabular}{ccccc}
\hline Parameter & Notation & Value & Units & Source \\
\hline Temp. inlet & $T_{\text {in } W}$ & 303.15 & $\mathrm{~K}$ & {$[25]$} \\
Temp. outlet & $T_{\text {out } w}$ & 308.15 & $\mathrm{~K}$ & {$[25]$} \\
Specific heat capacity & $C_{p W}$ & 4.178 & $\mathrm{~kJ} / \mathrm{kg} \cdot \mathrm{K}$ & {$[19]$} \\
Mass flow rates & $m_{W}$ & 0.03 & $\mathrm{~kg} / \mathrm{s}$ & {$[25]$} \\
Temp. inlet & $T_{\text {in } b}$ & 297.15 & $\mathrm{~K}$ & {$[25]$} \\
Temp. outlet & $T_{\text {out } b}$ & 301.15 & $\mathrm{~K}$ & {$[25]$} \\
Specific heat capacity & $C_{p b}$ & 1.0047 & $\mathrm{~kJ} / \mathrm{kg} \cdot \mathrm{K}$ & {$[19]$} \\
Mass flow rates & $m_{b}$ & 0.483 & $\mathrm{~kg} / \mathrm{s}$ & {$[25]$} \\
\hline
\end{tabular}


change in air operating conditions, air only cooling has a higher temperature increase across the conditions. Hybrid cooling benefits from placing less stress on the CRAC (Computer Room Air Conditioning unit) due to the water loop removing most of the heat. The air-cooling loop (denoted as $b$ to distinguish from air only cooling notation) in hybrid is a secondary contributor to the cooling, as such the inlet and outlet temperature are lower than air only cooling.

Hybrid cooling utilizes the same method as air cooling for calculating entropy generation and exergy, although the air and water loops are coupled; this is due to the systems being isolated from one another yet being capable of other recovering heat. The hybrid cooling thermodynamic analysis is described using Equation (2) for air and water loops. Equation (8) shows the two isolated systems and their coupled relationship. The data from Table 2 can be used to fill the equation parameters.

$$
\sum S_{\text {gen }}=\left[\frac{Q}{T_{a m b}}+\dot{m}\left(S_{3}-S_{4}\right)\right]_{\text {water }}+\left[\frac{\left[\dot{m} C_{p}\left(T_{2}-T_{1}\right)\right]}{T_{a m b}}+\dot{m}\left(C_{p} \times \ln \left(\frac{T_{2}}{T_{1}}\right)\right)\right]_{\mathrm{air}}
$$

The results for hybrid cooling are an entropy generation of $0.013 \mathrm{~kJ} / \mathrm{kg} \cdot \mathrm{K}$ for the air loop, and $60.5 \times 10^{-6} \mathrm{~kJ} / \mathrm{kg} \cdot \mathrm{K}$ for the water loop. Giving a combined entropy generation of $0.013 \mathrm{~kJ} / \mathrm{kg} \cdot \mathrm{K}$ for hybrid cooling. Applying this to Equation (8) gives exergy destroyed of $3.82 \mathrm{~kJ} / \mathrm{kg}$.

\subsubsection{Immersion Cooling}

Immersion cooling is a closed loop cooling method, on the contrary to the air and hybrid cooling techniques that are treated as open systems. Figure 6 shows the boundary conditions and analysis points for bath immersion cooling. Table 3 shows the typical operating conditions for immersion cooling.

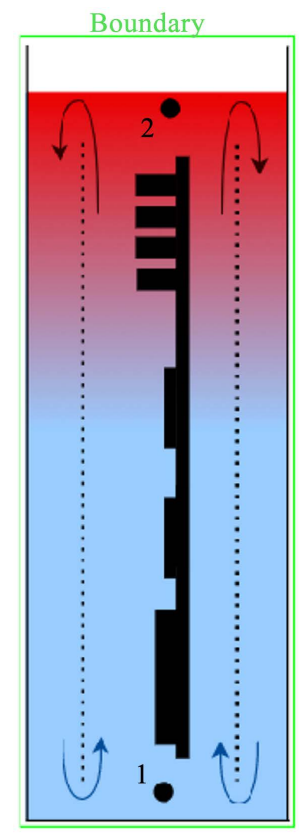

Figure 6. Bath immersion cooling blade server boundary conditions. 
Table 3. Immersion cooling data centre study parameters ( $T_{2}$ is assumed to be the boiling point of the dielectric coolant $+1 \mathrm{~K})$.

\begin{tabular}{ccccc}
\hline Parameter & Notation & Value & Units & Source \\
\hline Temperature at point 2 & $T_{2}$ & 335.15 & $\mathrm{~K}$ & Assumed \\
Temperature at point 1 & $T_{1}$ & 334.15 & $\mathrm{~K}$ & {$[26]$} \\
Dielectric specific heat capacity & $C_{\text {avg }}$ & 1.17 & $\mathrm{~kJ} / \mathrm{kg} \cdot \mathrm{K}$ & {$[27]$} \\
Water specific heat capacity & $C_{p}$ & 4.178 & $\mathrm{~kJ} / \mathrm{kg} \cdot \mathrm{K}$ & {$[19]$} \\
Temperature at condenser loop out & $T_{3}$ & 311.45 & $\mathrm{~K}$ & {$[26]$} \\
Temperature at condenser loop in & $T_{4}$ & 307.25 & $\mathrm{~K}$ & {$[26]$} \\
Condenser loop mass flow rate & $\dot{m}_{\text {win }}$ & 0.068 & $\mathrm{~kg} / \mathrm{s}$ & {$[26]$} \\
Ambient temperature of data centre & $T_{\text {amb }}$ & 295.15 & $\mathrm{~K}$ & {$[26]$} \\
\hline
\end{tabular}

Equation (9) shows the closed loop entropy balance equation from Cengel et al. [17]. The entropy from the surroundings $\left(S_{\text {surr }}\right)$ is due to the external condenser loop, this removes all excess heat from the dielectric bath.

$$
S_{\text {gen }}=\Delta S_{\text {sys }}-\Delta S_{\text {surr }}=m\left(C_{\text {avg }} \times \ln \left(\frac{T_{2}}{T_{1}}\right)\right)-\frac{\left[\dot{m} C_{p}\left(T_{3}-T_{4}\right)\right]}{T_{a m b}}
$$

Tuma (2015) performed a series of studies on two-phase immersion cooling with $3 \mathrm{M}$ and published two analogous experiments with different coolants in both cases. One experiment gives the server unit dimensions and a coolant that boils at $49^{\circ} \mathrm{C}$ [15]. The other experiment gives a full thermal breakdown for required figures, as it uses a dielectric with a boiling point of $61^{\circ} \mathrm{C}$ [26]. In this study, the mass of a single server unit is estimated using the first experiment [15], and the dimensions given are $20 \times 2.5 \times 30 \mathrm{~cm}(\mathrm{H} \times \mathrm{W} \times \mathrm{D})$ [15]. The thermal requirements are used from the second study [26].

The coolant used in the second study is $3 \mathrm{M}$ Novec $7100 \mathrm{DL}$. Using the dimensions from the first study: the server volume is $1500 \mathrm{~cm}^{3}$ and the density of the $3 \mathrm{M}$ Novec 7100DL is $1.52 \mathrm{~g} / \mathrm{cm}^{3}$ [27]. Supplying the server cooling unit with a coolant mass of $2.28 \mathrm{~kg}$, Equation (9) and data from Table 3 yielded results of $1.48 \mathrm{~kJ} / \mathrm{kg}$.

Exergy destroyed to Maximum Recoverable Waste Heat (MRWH) conversion is done by multiplying the exergy destroyed by the mass flow rate. For air cooling, this yields a MRWH of $9.2 \mathrm{~kJ} / \mathrm{s}$. Multiplying the MRWH by the Carnot efficiency $\left(T_{\text {out }}-T_{\text {in }} / T_{\text {out }}\right.$ ) gives the Recoverable Carnot Equivalent Power (RCEP). For the air-cooling systems and the study parameters, this is $0.39 \mathrm{~kW}$. The same method can be applied to hybrid (MRWH of $2.84 \mathrm{~kJ} / \mathrm{s}$ and a RCEP of $0.025 \mathrm{~kW}$ ) and immersion (MRWH of $0.08 \mathrm{~kJ} / \mathrm{s}$ and a RCEP of $0.0001 \mathrm{~kW}$ ) cooling techniques. The final RCEP values are shown in Figure 7.

\section{Theory and Results}

\subsection{Technical Analysis}

The thermodynamics analysis indicates a preference for air cooling in terms of 


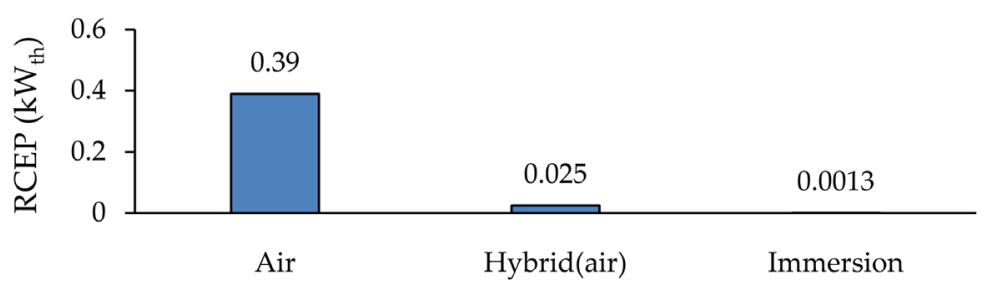

Figure 7. Maximum recoverable waste heat from the three cooling approaches considered in this study, for a single rack in a generic data centre environment. These calculations are based on this studies parameter. Further optimisation to increase heat recovery can be determined by altering input parameters.

heat recovery. In this section, the idea of data centres recovered heat being financially competitive with conventional means such as a Combined Heat and Power (CHP) unit or gas-fired boilers is explored. The application of the recovered heat from the data centre is considered in the context of Irish industries.

\subsubsection{Maximum Recoverable Waste Heat from Yearly Operation}

Data centres operate $50 \%$ percent of the year as previously stated, and this results in 4380 operating hours for the data centre per year. Estimation on the average number of racks per data centre in Ireland is 2360 racks per data centre (average rack is assumed to be $5 \mathrm{~kW}$, with 60 data centres at $708 \mathrm{MW}$ power capacity). Equation (10) shows the formula to determine yearly RCEP from a data centre. Equation (10) is applied to immersion cooling and hybrid (combined water and air loop) with MRWH values listed in Table 4. When isolated, the air loop recovers just $88 \mathrm{kWh}_{\mathrm{th}} / \mathrm{yr}$, and the water loop recovers the remainder.

$$
\operatorname{RCEP}_{\mathrm{DC}}=0.5 \times 8760 \mathrm{hr} \times 2360 \text { racks } \times \mathrm{MRWH}_{\mathrm{a}}
$$

\subsubsection{Optimisation of Heat Recovery for the Irish Data Centre Market}

Other studies in airside hybrid cooling optimisation determined that outlet temperature maximisation and flow rates contribute to entropy generation minimisation [28]. For optimal heat recovery, entropy generation is desired to be increased. Sakanova et al. (2019) recommend increasing the flow rate and the outlet server temperature will increase cooling performance [29]. This study determines this would decrease useable recoverable heat and to increase useable heat recovery. As such Sakanova et al. (2019) can provide the optimisation foundations to increase useable heat recovery, as shown below and in greater detail in Figure 8.

The optimisation process for this study considers the mass flow rate and ambient temperature as constant (constants: $\Delta T, \dot{m}, T_{a m b}$ ). The specific heat capacity is a function of the inlet and outlet temperatures, as such is calculated for each point. Varying the inlet temperatures to the minimum inlet temperature of ASHRAE TC9.9 $(288.15 \mathrm{~K})$ would yield an input power to recoverable heat percentage of $7.98 \%$ (listed in Table 5); raising the inlet temperature to the maximum ASHRAE TC9.9 limit ( $318.15 \mathrm{~K}$ ) yields $6.92 \%$ as shown in Figure 8. This is the highest heat recovery that can be expected given the conditions outlined. 


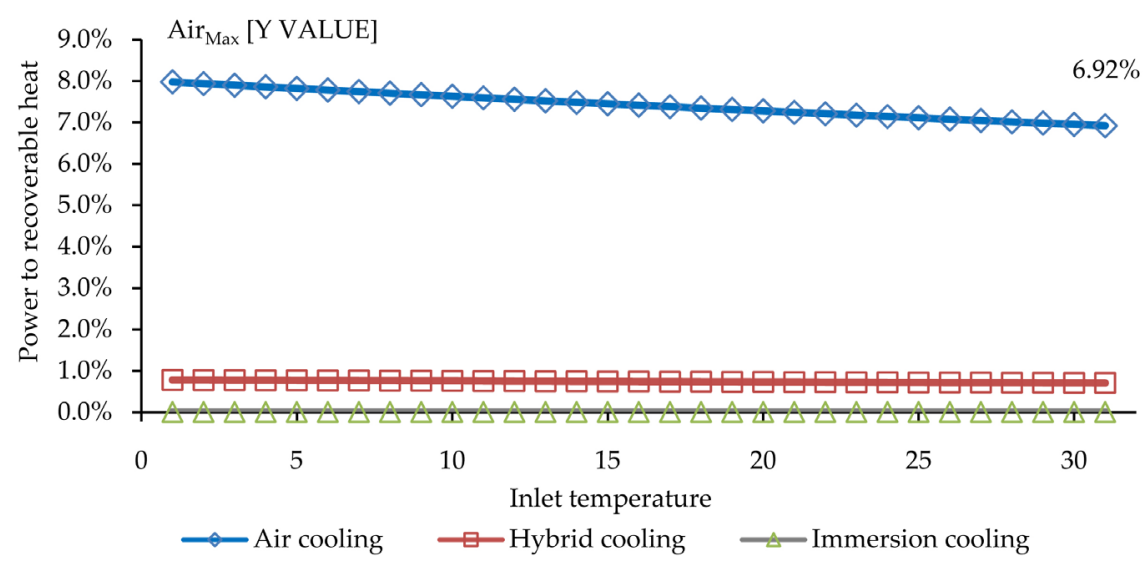

Figure 8. Maximum recoverable heat for $100 \%$ of the Irish data centre market using different cooling methods, as a function of inlet temperature (Air inlet range is $288.15 \mathrm{~K}$ to $318.15 \mathrm{~K}$. Hybrid (air) range is $288.15 \mathrm{~K}$ to $318.15 \mathrm{~K}$. Immersion (condenser loop) range is $290.15 \mathrm{~K}$ to $320.15 \mathrm{~K})$.

Table 4. Maximum recoverable waste heat per year from a single data centre, $25 \%, 50 \%$ and $100 \%$ of the Irish data centre market (as of July 2020 [3]) for air, hybrid and immersion cooling.

\begin{tabular}{ccccc}
\hline & Units & Air & Hybrid (combined) & Immersion \\
\hline Single data centre & $\mathrm{kWh}_{\text {th }} / \mathrm{yr}$ & $4,031,352$ & 258,420 & 13,438 \\
25\% Irish industry & $\mathrm{kWh}_{\text {th }} / \mathrm{yr}$ & $60,470,280$ & $3,876,300$ & 201,570 \\
$50 \%$ Irish industry & $\mathrm{kWh}_{\text {th }} / \mathrm{yr}$ & $120,940,560$ & $7,752,600$ & 403,140 \\
$100 \%$ Irish industry & $\mathrm{kWh}_{\text {th }} / \mathrm{yr}$ & $241,881,120$ & $15,505,200$ & 806,280
\end{tabular}

Table 5. Instantaneous maximum recoverable waste heat from the Irish data centre industry using air, hybrid and immersion cooling. The industry capacity is $708 \mathrm{MW}$ [3].

\begin{tabular}{ccc}
\hline Cooling type & Recoverable heat $\left(\mathrm{MW}_{\text {th }}\right)$ & Input power to heat recoverable ratio \\
\hline Air & 55.20 & $7.797 \%$ \\
Hybrid (combined) & 3.54 & $0.500 \%$ \\
Immersion & 0.18 & $0.025 \%$ \\
\hline
\end{tabular}

Further optimization is possible by changing the flow rate, and possible cooling gas composition (nitrogen, argon etc.). Data centres that do not adhere to the ASHRAE TC9.9 standard can increase their heat recovery potential further by increasing the inlet temperature beyond the ASHRAE upper limit. Due to the high number of hyperscale data centres in Ireland, the government could create a custom policy to improve recovery potential in this data center type.

The same method is applied to hybrid and immersion cooling in Figure 8. For hybrid cooling, the water loop temperature was constant in addition to the similar parameters as air cooling. For immersion cooling, the inlet temperature of the condenser loop was varied, due to the mechanism of operation for the boiling of the dielectric liquid. The variables were within the maximum and mini- 
mum operating conditions for all three cooling methods. The hybrid input power to recoverable heat range is $0.78 \%$ to $0.71 \%$. For immersion, it is constant at $0.01 \%$ shown on the same axis.

\subsection{Economic Analysis}

\subsubsection{Data Centre Cooling Costs}

To determine the heat recovery cost, the cost of running a data centres cooling system in Ireland must be considered. The same capacity factor as outlined in Section 1.1 is used in conjunction with a lower Levelized Cost of Electricity (LCOE) of $0.1 € / \mathrm{kWh}$, with the nationwide average assumed to be $0.17 € / \mathrm{kWh}$. Some industry rates are marginally lower, as accounted for here. The PUE scores are used here to determine the excess electricity that is not the IT load. These calculations are based on a single server. There is an assumption that the PUE score is for cooling only and not including lighting or power supply losses as generally, these are negligible compared to cooling. This is reflected in Equation (11) and used for calculations of the cooling system running cost. It is important to note PUE scoring is not formally standardised across data centres yet, and as such should be considered lightly reliable. There are only best practices and industry guidelines for determining PUE scores. Figure 9 shows the result of the yearly operational cost for the three cooling methods using Equation (11) in a generic Irish data centre (2360 servers). The total cost of electricity for a generic Irish data centre can be found in Table 6.

$$
\text { Cost }_{\text {cooling }}=C_{\text {factor }} \times 8760 \mathrm{hr} \times(\mathrm{PUE}-1) \times \mathrm{LCOE} \times 2360 \text { racks }
$$

\subsubsection{Data Centre Electricity Costs}

To determine the cost of running a data centre, Equation (11) can be modified and applied with the modification made to the PUE score taking it as a whole

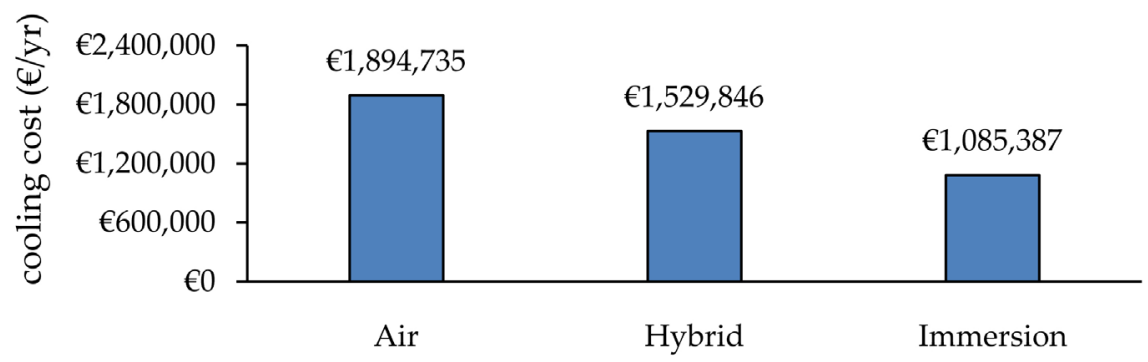

Figure 9. Yearly operational cost for generic Irish data centre cooling (2360 servers).

Table 6. Cost of operating a data centre, the RCEP and cost of heat recovered for the three core cooling methods.

\begin{tabular}{ccccc}
\hline & Units & Air & Hybrid (combined) & Immersion \\
\hline RCEP & $\mathrm{kWh}_{\mathrm{th}} / \mathrm{yr}$ & $4,031,352$ & 258,420 & 13,438 \\
Cost of DC & $€ / \mathrm{yr}$ & $€ 1,894,735$ & $€ 1,529,846$ & $€ 1,085,387$ \\
Cost of heat & $€ / \mathrm{kWh}_{\mathrm{th}}$ & $€ 0.47$ & $€ 5.92$ & $€ 80.77$ \\
\hline
\end{tabular}


load, rather than isolating the cooling load. Table 6 shows the coupled hybrid cooling. It is important to note air recovers minimal amounts of heat in the hybrid configuration and as such water should be targeted for waste heat recovery from a financial perspective. The cost of heat is the Cost of DC operation divided by the RCEP.

\section{Discussion}

\subsection{Waste Heat Recovery Applications}

Table 7 contains examples of generic Irish industries that could utilised data centre recovered heat; other applications are possible for the recovered heat. It follows a similar format to Ebrahimi et al. [20], but accounting for the lower exhaust temperatures. There also is the addition of Irish specific industries like agriculture and brewing. These calculations are based on the assumptions in Section 2.1. It is important to note the limitations of each technology and its heat recovery potential. Air cooling is limited by the heat capacity of air as it is low compared to other technologies. The temperature difference across the inlet and outlet of the hybrid air portion is lower due to the water loop removing most of the heat, thus the air cooler portion can operate at a lower capacity and the water portion should be targeted for heat removal. Immersion cooling is limited to the coolant fluid max temperature and its evaporation limit $\left(\right.$ c. $\left.70^{\circ} \mathrm{C}\right)$.

\subsection{Teagasc Research Centre Case Study}

Consider one possible application for the waste heat, general district heating. In October 2016 SEAI performed a district heating analysis on different sites within Ireland. One of the sites considered for a district heating system was Teagasc

Table 7. Waste heat recovery methods specific to Irish industries.

\begin{tabular}{cccccc}
\hline Industry & Heat application & Air & Hybrid (water) & Hybrid (air) & Immersion \\
Food & Exhaust heat temp. (K) & 303 & 308 & 301 & 307 \\
Absorption refrigeration & No & Yes & No & Yes \\
Power generation & Biomass fermentation & Yes & Yes & Yes & Yes \\
Power generation & Boiler feedwater heating & No & Yes & No & Yes \\
Water processing & Desalination/preheater & No & Yes & No & Yes* \\
Social & General district heating & Yes & Yes & Yes & Yes \\
Social & Domestic hot water & Yes & Yes & Yes & Yes \\
Agricultural & Drying of crops & Yes & No & Yes & No \\
Energy generation & Organic rankine cycle & Yes & Yes & No & Yes \\
Energy generation & Piezoelectric & Yes & No & No & Yes \\
Food & Private bread making & No & Yes & No & Yes \\
Food-brewing & Private fermentation & Yes & Yes & Yes & Yes \\
Energy generation & Thermoelectric & No & No & No & Yes \\
\hline
\end{tabular}

${ }^{\star}$ With a booster unit (e.g. heat pump); ${ }^{* *}$ with a step-down unit (e.g. chiller). 
Grange research centre in Co. Meath, Ireland [30]. Currently, the site uses several boilers for heating. The case study considered using a Combined Heat and Power (CHP) unit instead of several boilers. This article will consider using a data centre to provide heat instead of boilers or combined heat and power units. This case study only considers operational cost, not capital cost.

The boiler supply was determined to be $0.07 € / \mathrm{kWh}_{\text {th }}$ from the case study. The CHP was biogas fed from an onsite Anaerobic Digestion (AD) tank increasing the overall load by $410 \mathrm{MWh}_{\mathrm{th}}$. The CHP total load is $820 \mathrm{MWhth}$ per year [30]; the gas load to meet the thermal demand is $65,200 \mathrm{~m}^{3} / \mathrm{yr}$ of biogas [30]. The price of onsite biogas using farm waste is $0.33 € / \mathrm{m}^{3}$ [31]. This gives a yearly fuel cost of $€ 21,516$ per year. This then gives a heat cost of $0.026 € / \mathrm{kWh}_{\text {th }}$. The case study [30] considered a REFIT license for the combined heat and power unit which allows all excess electricity to be resold to the electricity grid. The REFIT license allows for the CHP to be used as a boiler to primarily provide heat, and then a generator to create electricity for use and resell.

Comparing the data centre recovered heat cost, and the traditional methods of heat production, it was determined to not be financially viable given no other costing strategies. Considering the cost of cheapest data centre method (air cooling) at $0.47 € / \mathrm{kWh}_{\text {th }}$ is far greater than boiler cost of $0.07 € / \mathrm{kWh}_{\text {th }}$ and $\mathrm{CHP}$ cost of $0.026 € / \mathrm{kWh}_{\text {th }}$, it is unlikely to see direct resell strategies in Irish data centres.

One strategy that could make data centres more competitive in reselling of heat is price offsetting. If an air-cooled data centre was to generate $€ 2$ million in additional revenue from its IT systems, then the cost of reselling heat is reduced to $0.01 € / \mathrm{kWh}_{\text {th. }}$. It is important to note in this case Data centres as a corporate tool must be profitable, data centres currently do not resell heat; as such it is likely already profitable to operate a data centre without the resell heat. This means data centres could give the current market climate set, their own resell price to be competitive with traditional means; rather than relying on matching current cost, data centres could price match marginally traditional means to resell heat. This is shown in Table 8.

\subsection{Data Centre Cooling, Growth and Link to Emissions}

A current grid growth projection for 2040 in Ireland is 47.1 TWh per annum (median projections) [32]. Assuming a linear growth of demand, 2050's required consumption is 55.3 TWh per annuum. To meet this demand, Ireland will have to provide an increase of 24.6 TWh generation capacity (additional yearly production capacity), in addition to decarbonising the grid by a further $47.8 \%$ with

Table 8. Heat cost of boilers, CHP, data centre air cooling direct and offset data centre air cooling.

\begin{tabular}{cccccc}
\hline & Units & Boiler & CHP & Data centre (air) & Data centre offset (air) \\
\hline Recovery cost & $€ / \mathrm{kWh}_{\text {th }}$ & 0.026 & 0.07 & 0.47 & 0.01 \\
\hline
\end{tabular}


Table 9. Electricity and emission reduction from using hybrid or immersion cooling within generic Irish data centres.

\begin{tabular}{ccccc}
\hline Property & Units & Air & Hybrid & Immersion \\
\hline Total electricity capacity & MW & 658 & 533 & 378 \\
Total electricity consumed & TWh/yr & 4.32 & 3.50 & 2.48 \\
Total electricity change & $\%$ & Baseline & -19.0 & -42.6 \\
Emission responsible & $\mathrm{Gg} \mathrm{CO}_{2} / \mathrm{yr}$ & 1.9 & 1.5 & 1.1 \\
Emission reduction & $\%$ & Baseline & -21.0 & -42.1 \\
Cooling electricity load & $\mathrm{MW}$ & 298 & 173 & 18 \\
Cooling electricity consumed & $\mathrm{TWh} / \mathrm{yr}$ & 1.96 & 1.14 & 0.12
\end{tabular}

renewable sources to meet NREAP (National Renewable Energy Action Plan) targets ${ }^{2}$. This indicates the data centres industries responsibility to assist these goals, given the significant portion of Ireland's electricity consumption by 2025 and beyond by data centres. Currently, Irish Data centres are entirely using the air-cooling technique, this is then used as the baseline for comparison to investigate the possible benefits in the total load, cooling load, and emissions from data centres. There is a significant reduction in electricity consumed and emissions when hybrid or immersion cooling is used over air cooling in Irish data centres as shown in Table 9. The capacity factor and emission intensity are the same as stated in Section 1.1.1 prior.

\section{Conclusion}

Energy consumption in Irish data centres is set to double by 2025. If data centres are to respond to the EU's current trends of decarbonization, then reformative actions are required in Irish data centres. "Shaping Europe's Digital Future" published in February 2020 by the EU outlined that data centres as an industry of Europe must become more sustainable. It does not outline methods to achieve this, although does mention the need for Initiatives to achieve carbon-neutral, energy-efficient sustainable data centres. Two possible methods to achieve these targets are the resell of heat or to reduce overall electricity consumption from alternative cooling methods, as both discussed in this study.

\subsection{Engineering}

Data centres rely on standards, currently, ASHRAE TC9.9 is the most prevalent cooling standard for data centres. Hybrid and immersion cooling methods have no standards available and as such are limited in adoption. Their performance is far greater than air cooling, in reduced electricity consumption, reduced emission and increased power density.

Air cooling has a Recoverable Carnot Equivalent Power (RCEP) of $0.39 \mathrm{~kW} /$ rack. Hybrid cooling has a RCEP of $0.025 \mathrm{~kW} /$ rack. Immersion cooling has a RCEP of

${ }^{2}$ https://www.dccae.gov.ie/en-ie/energy/topics/Renewable-Energy/irelands-national-renewable-energ y-action-plan-(nreap)/Pages/Action-Plan.aspx 
$0.013 \mathrm{~kW} / \mathrm{rack}$. This means that Irish data centres have the engineering potential to be heat providers.

It was determined in Section 3.2 that for a generic Irish data centre immersion cooling was the cheapest cooling method on average costing $€ 1,085,387$ per year in the cooling cost. Hybrid cooling was second at $€ 1,529,846$ cooling costs per year. Air cooling was the most expensive cooling method at $€ 1,894,735$ per year.

\subsection{Financial}

The resell of heat was determined to be financially viable in Irish data centres. Of the three cooling methods and their respective heat recovery, none were determined to be economically justifiable in a direct strategy. The direct strategy is selling directly to a heat consumer with no cost reduction from selling the data centres IT load, or REFIT licensing. The data centre must generate additional income to offset the waste heat recovered price, this is where the data centre IT system can be used to reduce the cooling cost. It is important to note that this is the best-case scenario by recovering all the recoverable heat (real-world applications would have recovery unit losses) and selling at the lowest cost possible. It is likely the price of heat will be higher due to less heat being recovered in a real-world application.

A case-by-case approach to determine optimal operating conditions and price is required to maximise its benefits. Air cooling was determined to be the most financially viable method of waste heat recovery in data centres, with hybrid and immersion cooling being unlikely to become competitive through offset or direct strategies alone. This study uses generic Irish and EU data centre operating conditions and as such a further optimisation could yield better results.

Air recovery cost was $0.47 € / \mathrm{kWh}_{\text {th }}$. Hybrid was $5.92 € / \mathrm{kWh}_{\text {th }}$ and immersion was $80.77 € / \mathrm{kWh}_{\text {th }}$. When compared to traditional methods: A gas boiler heating cost is $0.07 € / \mathrm{kWh}_{\text {th }}$, a biogas fired combined heat and power unit is $0.03 € / \mathrm{kWh}_{\text {th. }}$. The recovery of heat in a data centre is not financially competitive with the current market supply without alternative strategies.

\subsection{Environmental}

The reduction of overall electricity consumption can be assisted greatly through alternative cooling methods. A reduction of 19\% using hybrid cooling or $43 \%$ using immersion cooling can be seen in overall electricity consumption in switching from air to immersion cooling. This in turn reduces the overall emissions by the same amount.

If the electricity consumption is unchangeable for data centres, due to the limited adoption of hybrid and immersion cooling, there are three options that the Irish government can undertake to reduce the industries emissions:

1) Reduce the carbon intensity of the Irish electricity grid.

2) Generate carbon-free electricity (solar, wind, etc.) on the site of the data centre. 
3) Offset the carbon emission from electricity consumed within the data centre (carbon capture).

The Irish data centre industry has already set ambitious sustainability goals such as setting the goal of being carbon neutral from 2030 and beyond. The resell of heat, alternative cooling methods, or carbon reduction methods are all additional sustainability mechanisms. It is unlikely there will be a one-size fits all data centres solution, but a combination of the three methods above could see greener, more sustainable data centres in Ireland.

\section{Acknowledgements}

The authors would like to thank the School of Mechanical and Design Engineering at Technological University Dublin for their support in this publication. This publication has emanated from research conducted with the financial support of Science Foundation Ireland under the SFI Strategic Partnership Programme Grant Number SFI/15/SPP/E3125.

\section{Conflicts of Interest}

The authors declare no conflicts of interest regarding the publication of this paper.

\section{References}

[1] Google (2020) Google Data Centers Efficiency. https://www.google.com/about/datacenters/efficiency/

[2] Ni, J. and Bai, X. (2017) A Review of Air Conditioning Energy Performance in Data Centers. Renewable and Sustainable Energy Reviews, 67, 625-640. https://doi.org/10.1016/j.rser.2016.09.050

[3] Connolly, G. (2020) 2020 Q1 Irish Data Centre Market Report. Host in Ireland, Dublin.

[4] Gibbons, L., Coyne, B., Kennedy, D. and Alimohammadi, S. (2019) A TechnoEconomic Analysis of Current Cooling Techniques in Ireland Data Centres. 2019 25th International Workshop on Thermal Investigations of ICs and Systems (THERMINIC), Lecco, 25-27 September 2019, 1-6. https://doi.org/10.1109/THERMINIC.2019.8923482

[5] Met, Eireann (2020) Monthly Values for PHOENIX PARK up to 04-Jul-2020. https://www.met.ie/climate/available-data/monthly-data

[6] Connolly, G. (2019) Ireland's Data Hosting Industry Q1 2019 Update. Host in Ireland, Dublin.

[7] Connolly, G. and McAuley, D. (2020) 2020 Q1 Irish Data Centre Market Report. Host in Ireland, Dublin.

[8] Sustainable Eenergy Authority of Ireland (2019) Energy in Ireland 2019. Sustainable Energy Authority of Ireland, Dublin.

[9] Eirgrid (2016) Eirgrid Generation Capacity Statement. Eirgrid, Dublin.

[10] Van De Voort, T., Zavarel, V., Galdiz, I.T. and Hensen, J. (2017) Analysis of Performance Metric for Data Cnetre Efficiency. REHVA (Representatives of European Heating and Ventilation Associations) Journal, 1-11. 
https://research.tue.nl/en/publications/analysis-of-performance-metrics-for-data-ce nter-efficiency-should-2

[11] Connolly, G. and McAuley, D. (2020) Ireland's Data Hosting Industry Q3 2019 Update. Host in Ireland, Dublin.

[12] Eirgrid and SONI (2019) All-Island Generation Capacity Statement 2019-2028. Eirgrid, Belfast/Dublin.

[13] Avgerinou, M., Bertoldi, P. and Castellazzi, L. (2017) Trends in Data Centre Energy Consumption under the European Code of Conduct for Data Centre Energy Efficiency. Energies, 10, Article No. 1470. https://doi.org/10.3390/en10101470

[14] Acton, M., Bertoldi, P. and Booth, J. (2020) Best Practice Guidelines for the EU Code of Conduct on Data Centre Energy Efficiency. European Union Joint Research Centre, Luxembourg.

[15] Tuma, P.E. (2015) The Merits of Open Bath Immersion Cooling of Datacom Equipment. 3M Center, Saint Paul, Minnesota, USA.

[16] Sverdlik, Y. (2014) Is Direct Liquid Cooling Making a Comeback? Data Center Knowledge.

https://www.datacenterknowledge.com/archives/2014/08/14/is-direct-liquid-coolin g-making-a-comeback

[17] Cengel, Y. and Boles, M. (2014) Thermodynamics: An Engineering Approach. 8th Edition, McGraw-Hill Education Europe, London, UK.

[18] Capozzoli, A. and Primiceri, G. (2015) Cooling Systems in Data Centers: State of Art and Emerging Technologies. Energy Procedia, 83, 484-493. https://doi.org/10.1016/j.egypro.2015.12.168

[19] Rogers, G. and Mayhew, Y. (1996) Thermodynamics and Transports Properties of Fluids. 5th Edition, Blackwell Publishing, Hoboken, New Jersey, USA.

[20] Ebrahimi, K., Jones, G.F. and Fleischer, A.S. (2014) A Review of Data Center Cooling Technology, Operating Conditions and Corresponding Low-Grade Waste Heat Recovery Opportunities. Renewable and Sustainable Energy Reviews, 31, 622-638. https://doi.org/10.1016/j.rser.2013.12.007

[21] Wang, I.-N., Tsui, Y.-Y. and Wang, C.-C. (2015) Improvements of Airflow Distribution in a Container Data Center. Energy Procedia: Clean, Efficient and Affordable Energy for a Sustainable Future: The 7 th International Conference on Applied Energy (ICAE 2015), 75, 1819-1824. https://doi.org/10.1016/j.egypro.2015.07.153

[22] Wibron, E., Ljung, A.-L. and Lundstrom, T.S. (2019) Comparing Performance Metrics of Partial Aisle Containments in Hard Floor and Raised Floor Data Centers Using CFD. Energies, 12, Article No. 1473. https://doi.org/10.3390/en12081473

[23] Yan. B., Gu, L. and Xiao. Q. (2018) Comparative Study of Energy Performance between Chip and Inlet Temeprature-Aware Workload Allocation in Air-Cooled Data Center. Energies, 11, Article No. 669. https://doi.org/10.3390/en11030669

[24] Alimohammadi, S. and Persoons, T. (2020) A Novel Linear Air Amplifier Technology to Replace Rotary Fans in Data Center Server Rack Cooling. 2020 26th International Workshop on Thermal Investigations of ICs and Systems (THERMINIC), Berlin, 14 September-9 October 2020, 1-6. https://doi.org/10.1109/THERMINIC49743.2020.9420492

[25] Carbo, A., Oro, E., Salom, J., Canuto, M., Macias, M. and Guitart, J. (2016) Experimental and Numerical Analysis for Potential Heat Reuse in Liquid Cooled Data Centres. Energy Conversion and Management, 112, 135-145.

https://doi.org/10.1016/j.enconman.2016.01.003 
[26] Tuma, P.E. (2012) Open Bath Immersion Cooling: Density, Efficeincy and Simplicity. Datacenter Dynamics Converged, Paris.

[27] $3 \mathrm{M}^{\mathrm{TM}}$ Novec ${ }^{\mathrm{TM}} 7100$ Engineered Fluid Spec Sheet. 3M Company, Saint Paul, Minnesota, USA.

[28] Sakanova, A., Alimohammadi, S., McEvoy, J. and Persoons, T. (2018) Hybrid-Cooled Data Center Server Layout Optimization for Air-Side Heat Recovery. 2018 24th International Workshop on Thermal Investigations of ICs and Systems (THERMINIC), Stockholm, 26-28 September 2018, 1-4. https://doi.org/10.1109/THERMINIC.2018.8593309

[29] Sakanova, A., Alimohammadi, S., McEvoy, J., Battaglioli, S. and Persoons, T. (2019) Multi-Objective Layout Optimization of a Generic Hybrid-Cooled Data Centre Blade Serve. Applied Thermal Engineering, 156, 514-523. https://doi.org/10.1016/j.applthermaleng.2019.04.071

[30] Gartland, D. and Bruton, T. (2016) A Guide to District Heating in Ireland. SEAI.ie, Dublin, 27-33.

[31] Murphy, J.D. and O’Shea, R. (2019) Green Gas in the Energy Transition. 2019 MaREI Seminar on Climate Action Policy, Ringaskiddy, Co. Cork, Ireland (Remote), 20th May 2020, 8-12.

[32] EirGrid (2019) Tomorrow's Energy Scenarios 2019 Ireland-Planning Our Energy Future. EirGrid, Dublin. 